\title{
Heart Rate Recovery, Central Systolic Pressure, and Augmentation Index in Young Healthy Individuals
}

\author{
Peter L Latchman', Qin Yang ${ }^{2}$, Lingsong Kong $\mathbb{D}^{3}$, Hengbo Zhang ${ }^{4}$, Josephine Sebagisha ${ }^{5}$, \\ Ronald E De Meersman ${ }^{6}$ \\ 'Department of Health and Movement Sciences, Southern Connecticut State University, New Haven, CT, USA; ${ }^{2}$ School of Health Promotion and \\ Kinesiology, Texas Woman's University, Denton, TX, USA; ${ }^{3}$ Department of Kinesiology, University of Massachusetts, Amherst, MA, USA; ${ }^{4}$ College of \\ Physical Education, Hunan First Normal University, Changsha, People's Republic of China; ${ }^{5}$ Clinical Department St. James School of Medicine, Chicago, \\ IL, USA; ${ }^{6}$ Department of Rehabilitation and Regenerative Medicine, Columbia University, New York, NY, USA
}

Correspondence: Peter L Latchman, Department of Health and Movement Sciences, Southern Connecticut State University, 50I Crescent Street, New Haven, CT, 065I5, USA, Tel + I 203-392-608I, Fax + 203-392-6093, Email latchmanpI@southernct.edu

\begin{abstract}
Purpose: Measuring heart rate recovery (HRR) holds valuable cardiovascular information and requires minimal technical skill and cost. Understanding the associations between HRR and more robust cardiovascular indicators, such as central systolic blood pressure (CSBP), can provide valuable cardiovascular information with less involvement. CSBP is a strong predictor of certain cardiovascular diseases. The study aims to examine the association between measures of HRR and CSBP and the augmentation index (AIx) in a group of young, healthy individuals and based on sex.

Participants and Methods: One-hundred and seven participants (men - 55, women - 52) were measured for HRR at one minute $\left(\mathrm{HRR}_{1}\right)$ and two minutes $\left(\mathrm{HRR}_{2}\right)$ after maximum oxygen consumption $\left(\mathrm{VO}_{2 \max }\right)$ testing, $\mathrm{CSBP}$, and the AIx at a heart rate of 75 beats·min ${ }^{-1}$ (AIx@75).

Results: The Pearson correlation indicated no association between $\mathrm{HRR}_{1}, \mathrm{HRR}_{2}$, and CSBP in men and women combined: $\mathrm{r}=0.06, \mathrm{P}=0.53$; $r=0.05, P=0.59$, respectively, or based on sex: men $=r=0.01, P=0.95 ; r=0.04, P=0.79$, respectively, and women $=r=-0.05, P=0.75$; $\mathrm{r}=-0.09, \mathrm{P}=0.52$, respectively. However, there were associations between $\mathrm{HRR}_{1}$ and $\mathrm{AIx} @ 75$ in men and women combined: $\mathrm{r}=-0.37$, $\mathrm{P}<0.001$, and based on sex: $\mathrm{men}=\mathrm{r}=-0.31, \mathrm{P}=0.02$, and women $=\mathrm{r}=-0.38, \mathrm{P}<0.01$.

Conclusion: Measures of HRR were not associated with CSBP in a combined group of young men and women or based on sex. Most measures of HRR, especially those established by parasympathetic nervous activity, were associated with lower AIx@75. Though measures of HRR might be good indicators of cardiovascular disease, they might not be good indicators of CSBP in young, healthy individuals.
\end{abstract}

Keywords: heart rate recovery, central blood pressure, central systolic blood pressure, augmentation index, sex

\section{Introduction}

Heart rate recovery (HRR), which represents the difference between maximal heart rate and the heart rate during recovery from exercise, ${ }^{1,2}$ holds valuable cardiovascular and all-cause mortality information. ${ }^{3}$ Measuring HRR requires minimal technical skill and equipment, which makes HRR a good metric of cardiovascular function that can be used in a variety of settings. Though no epidemiological study has indicated that heart rate would interact with blood pressure significantly in cardiovascular risk prediction, slower HRR has been reported in older individuals with higher BP and stiffer arteries. ${ }^{4}$ Examining the association between HRR and more robust clinical measures of cardiovascular function in young people, for example, central systolic blood pressure (CSBP), a measure that requires technical skills and advanced equipment, could provide valuable cardiovascular information without high levels of technical skill and expensive equipment.

During graded exercise testing, there is significant but not total withdrawal of parasympathetic nervous activity $(\mathrm{PNA})^{5}$ and a concomitant increase in sympathetic nervous activity (SNA). ${ }^{6,7}$ Conversely, after exercise, there is PNA 
reactivation and SNA withdrawal, which promotes HRR. HRR is a commonly used indicator of parasympathetic activity ${ }^{8}$ and parasympathetic reactivation ${ }^{5}$ after exercise. During the first minute of HRR $\left(\mathrm{HRR}_{1}\right)$, PNA is considered to be the main determinant of heart rate reduction, ${ }^{9}$ while during the second minute of HRR $\left(\mathrm{HRR}_{2}\right)$, SNA withdrawal is considered to be a more significant contributor to HRR versus PNA. ${ }^{9}$ Additionally, delayed HRR is considered to be indicative of reduced PNA reactivation ${ }^{10,11}$ or reduced SNA withdrawal, ${ }^{5}$ or a combination of both depending on the time of HRR. Delayed HRR is associated with negative cardiovascular and respiratory health. ${ }^{3,12-14}$ Since HRR is indicative of PNA, the association between delayed HRR and cardiovascular health can perhaps be explained in part by the understanding that PNA can offer tonic restraint of SNA to the heart, as several cardiovascular diseases are associated with pronounced alterations in sympathetic control of circulation. ${ }^{15,16}$ While many factors have been demonstrated to affect HRR, sex has been demonstrated to be an important determinant of HRR. ${ }^{17}$

Central blood pressure is associated with increased arterial stiffness (AS) and has been suggested as being associated with cardiovascular events. ${ }^{18}$ The association between central blood pressure and negative cardiovascular outcomes can perhaps be explained in part by the understanding that central blood pressure reflects the load placed on the left ventricle and the coronary and cerebral vasculature. ${ }^{19}$ Though central blood pressure is more indicative of certain cardiovascular events, it is not truly superior to brachial blood pressure, and more recent work does not share the earlier enthusiasm for central blood pressure being a superior indicator of morbidity and mortality. ${ }^{20-22}$ Men have been noticed to have higher systolic blood pressure (SBP) up to age fifty versus women, while women have been shown to have greater systolic augmentation after the first decade, a difference that was significant after age $30 .{ }^{23}$ Additionally, hypertensive women have demonstrated both higher reflective aortic pressure waveform and central blood pressure indexes versus men. ${ }^{24}$ The augmentation index (AIx) is an important cardiovascular indicator. It has been shown to be robustly associated with systemic vascular resistance ${ }^{25}$ and is an independent predictor of cardiovascular events and mortality. ${ }^{26}$

Sex affects HRR, ${ }^{17}$ CSBP and cardiovagal tone as a predictor of aortic pressure augmentation. ${ }^{27}$ Therefore, it is possible that sex could influence the relationship between HRR and CSBP.

HRR is easily measured, requiring minimal technical skill and inexpensive equipment, and CSBP is a predictor of cardiovascular mortality. ${ }^{18}$ Understanding the associations then between measures of $\mathrm{HRR}\left(\mathrm{HRR}_{1}\right.$ and $\left.\mathrm{HRR}_{2}\right), \mathrm{CSBP}$, and central diastolic blood pressure (CDBP) could provide valuable information regarding cardiovascular function with relative ease.

Therefore, the aims of this study were to primarily examine the association between measures of HRR and CSBP in young healthy men and women combined and based on sex, and secondarily to examine the association between measures of HRR and AIx in the same groups.

\section{Materials and Methods}

This study included 107 young men and women $(\mathrm{M}=55, \mathrm{~W}=52)$ with a minimum age of 18 from the student population of Southern Connecticut State University and individuals from the local community. Inclusion criteria included no history of smoking and no clinical indications of cardiovascular, pulmonary, or metabolic disease, as well as being medication free with normal electrocardiogram (ECG) and blood pressure patterns. This study was conducted in accordance with the Declaration of Helsinki and was approved by the Institutional Review Board at Southern Connecticut State University.

Written informed consent was obtained from all participants. Participants arrived for testing between 7:00 and 10:00 a.m. Prior to arrival, they were advised not to exercise or consume food for 48 and 12 hours respectively but were allowed to drink water. Women participated in the study within the first five days after menstruation to standardize and minimize the influence of hormonal levels on autonomic function. ${ }^{28}$ Measurements were performed in a $21{ }^{\circ} \mathrm{C}$ temperature-controlled room. Anthropometric measurements were taken, and after 5 minutes of seated rest, two blood pressure measurements were taken if the first and second measurements were the same. Three blood pressure measurements were taken if the first and second measurements were different. These measurements were taken at 5 minute intervals, and the mean value of these measurements was used to indicate SBP and diastolic blood pressure (DBP). 


\section{Measures}

Central systolic blood pressure (CSBP), Central diastolic blood pressure (CDBP), and AIx at a heart rate of 75 beats·min ${ }^{-1}$ (AIx@75).

CSBP, CDBP, and AIx@75 were measured via applanation tonometry and pulse wave analysis using the SphygmoCor system (AtCor Medical Pty Ltd., West Ryde, Australia). The principle of applanation tonometry is based on Laplace's law. Here, the association between wall tension and the pressure difference between two sides of a wall and the radius of a cylindrical thin wall tube is taken into consideration. ${ }^{29}$

Measurements were taken from the left radial pulse after 6 minutes of rest in a seated position. Here, a high-fidelity transducer applanation tonometer was placed over the left radial pulse. The CSBP and CDBP were determined by measuring the peak and trough of the central pressure waveform. ${ }^{30}$ The AIx was established as the difference between the main outgoing wave and the reflected wave of the central waveform, expressed as a percent of the central pulse pressure. Since heart rate has an effect on pressure augmentation, ${ }^{31,32}$ AIx values were adjusted to a standard heart rate of 75 beats· $\min ^{-1}$, denoted by AIx@75. During the measurement, the SphygmoCor system analyzed the radial waveform via a generalized transfer function that was validated intra-arterially, ${ }^{33,34}$ determining CSBP, CDBP, and AIx@75. The SphygmoCor system automatically captured these measurements when the incorporated quality control component determined that the data were accurate. All collected data conformed to a research imposed $\geq 90 \%$ threshold of accuracy, determined by the system.

\section{Heart Rate Recovery (HRR)}

In an effort to obtain $\mathrm{HRR}_{1}$ and $\mathrm{HRR}_{2}$, participants performed a maximum oxygen consumption $\left(\mathrm{VO}_{2} \mathrm{max}\right)$ test. Values were derived using a ParvoMedics TrueOne 2400 metabolic measuring system (ParvoMedics, Sandy, UT). $\mathrm{VO}_{2} \mathrm{max}$ testing was performed on a computer-controlled, motorized Trackmaster Treadmill (Full Vision Inc., Newton, KS) using the Bruce Treadmill Protocol. ${ }^{35}$ The physical activity level of participants was assessed via the Borg rating of perceived exertion scale; this assessment being taken at the end of each protocol stage. The stage progressed from the previous one every 3 minutes by increasing the work rate (speed and grade), until $\mathrm{VO}_{2}$ max was reached. $\mathrm{VO}_{2}$ max was confirmed in all subjects by obtaining a combination of at least two of the four following criteria: a plateau in oxygen consumption despite an increased work rate; a respiratory exchange ratio (RER) $>1.10$; a heart rate within 10 beats $\cdot \mathrm{min}^{-1}$ of the agepredicted maximum (220-age); or volitional fatigue. Data from any participants who did not meet two of these criteria were not retained for analysis. $\mathrm{HRR}_{1}$ and $\mathrm{HRR}_{2}$ values were derived as the difference between maximal heart rate at $\mathrm{VO}_{2}$ max, and heart rate at one and two minutes into recovery, expressed as beats $\cdot \min ^{-}{ }^{1}$.

\section{Results}

Means and standard deviations for variables for the combined and separate groups of men and women are illustrated in Table 1. Independent $t$-test results based on sex are listed in Table 1 and indicated that there was no difference in age based on sex, but there was a difference in BMI. CSBP and CDBP pressures were higher in men versus women. $\mathrm{HRR}_{1}$ and $\mathrm{HRR}_{2}$ were higher in men versus women, however AIx@75 was higher in women versus men.

Pearson correlation results are listed in Table 2. There was no association between $\mathrm{HRR}_{1}$ and CSBP in the combined group of men and women (Figure 1) and there was also no association between $\mathrm{HRR}_{1}$ and central diastolic blood pressure in this group. However, there was an association between $\mathrm{HRR}_{1}$ and AIx@75 (p $=<0.001$ ) (Figure 2). Additionally, there was no association between $\mathrm{HRR}_{2}$ and CSBP or CDBP, but there was an association between $\mathrm{HRR}_{2}$ and AIx@75 (p=<0.001).

Table 2. In the men's group, there were no associations between $\mathrm{HRR}_{1}$ and CSBP (Figure 3) or CDBP. However, there was an association between $\mathrm{HRR}_{1}$ and AIx@75 $(\mathrm{p}=0.02)$ (Figure 4). In this group, there were no associations between $\mathrm{HRR}_{2}$ and CSBP, CDBP, or AIx@75.

Table 2. In the women's group, there were no associations between $\mathrm{HRR}_{1}$ and CSBP (Figure 5) or CDBP. However, there was an association between $\mathrm{HRR}_{1}$ and $\mathrm{AIx} @ 75(\mathrm{p}=<0.01)$ (Figure 6). In this group, there were no associations between $\mathrm{HRR}_{2}$ and CSBP, or CDBP, but there was an association with AIx@75 ( $\left.\mathrm{p}=<0.01\right)$. 
Table I Mean and Standard Deviation Values of Key Study Variables

\begin{tabular}{|c|c|c|c|c|}
\hline & Men $(n=55)$ & Women $(n=52)$ & $\mathbf{P}$ & Total $(n=107)$ \\
\hline Age & $21.6 \pm 3.3$ & $21.6 \pm 3.1$ & 0.977 & $21.6 \pm 3.2$ \\
\hline BMI $\left(\mathrm{kg} / \mathrm{m}^{2}\right)$ & $25.2 \pm 3.0$ & $23.8 \pm 3.5$ & 0.036 & $24.5 \pm 3.3$ \\
\hline $\mathrm{SBP}(\mathrm{mmHg})$ & $111.9 \pm 7.2$ & $105.2 \pm 7.0$ & $<0.001$ & $108.6 \pm 7.8$ \\
\hline $\mathrm{DBP}(\mathrm{mmHg})$ & $67.1 \pm 6.7$ & $62.8 \pm 5.3$ & $<0.001$ & $65.0 \pm 6.4$ \\
\hline $\mathrm{CSBP}(\mathrm{mmHg})$ & $96.8 \pm 7.5$ & $92.3 \pm 6.5$ & 0.001 & $94.6 \pm 7.3$ \\
\hline $\mathrm{CDBP}(\mathrm{mmHg})$ & $68.0 \pm 6.4$ & $64.2 \pm 5.4$ & 0.001 & $66.1 \pm 6.2$ \\
\hline RHR (beats $\min ^{-1}$ ) & $67.5 \pm 9.6$ & $72.9 \pm 10.7$ & 0.007 & $70.2 \pm 10.5$ \\
\hline HRmax (beats $\min ^{-1}$ ) & $191.9 \pm 8.8$ & $190.9 \pm 7.7$ & 0.533 & $191.4 \pm 8.3$ \\
\hline $\mathrm{HRR}_{\mathrm{I}}$ (beats $\mathrm{min}^{-1}$ ) & $19.9 \pm 8.9$ & $16.2 \pm 6.3$ & 0.017 & $18.1 \pm 7.9$ \\
\hline $\mathrm{HRR}_{2}$ (beats $\mathrm{min}^{-1}$ ) & $36.1 \pm 11.3$ & $30.8 \pm 11.2$ & 0.018 & $33.5 \pm 11.5$ \\
\hline Alx@75 beats $\min ^{-1}(\%)$ & $2.8 \pm 9.5$ & $8.5 \pm 11.3$ & 0.005 & $5.6 \pm 10.8$ \\
\hline $\mathrm{VO}_{2} \max \left(\mathrm{mL} \mathrm{kg}^{-1} \cdot \mathrm{min}^{-1}\right)$ & $48.9 \pm 7.3$ & $39.1 \pm 7.3$ & $<0.001$ & $44.1 \pm 8.8$ \\
\hline
\end{tabular}

Note: $P<0.05$

Abbreviations: Alx@75 beats min ${ }^{-1}$, augmentation index at a heart rate of 75 beats per minute; BMI, body mass index; CSBP, central systolic blood pressure; CDBP, central diastolic blood pressure; DBP, diastolic blood pressure; HRmax, maximal heart rate; $H R R_{1}$, heart rate recovery at the first minute of recovery; $H R R_{2}$, heart rate recovery at the second minute of recovery; RHR, rest heart rate; SBP, systolic blood pressure; $\mathrm{VO}_{2}$ max, maximal oxygen consumption.

Table 2 Pearson Correlation Results for Measures of HRR, Central Blood Pressures and the Augmentation Index at a Heart Rate of 75 Beats $\mathrm{min}^{-1}$ in Men, Women and a Combined Group

\begin{tabular}{|c|c|c|c|c|c|c|}
\hline \multirow[t]{2}{*}{ Variables } & \multicolumn{2}{|c|}{ Combined Group $(n=\mid 07)$} & \multicolumn{2}{|c|}{ Men Group $(n=55)$} & \multicolumn{2}{|c|}{ Women Group $(n=52)$} \\
\hline & HRR $_{\text {I }}$ & $\mathrm{HRR}_{2}$ & HRR $_{\text {I }}$ & $\mathbf{H R R}_{2}$ & HRR $_{\text {I }}$ & $\mathbf{H R R}_{2}$ \\
\hline CSBP & $0.06(P=0.53)$ & $0.05(P=0.59)$ & $0.01 \quad(P=0.95)$ & $0.04(P=0.79)$ & $-0.05(P=0.75)$ & $-0.09(P=0.52)$ \\
\hline CDBP & $0.08(P=0.4 I)$ & $0.13(P=0.19)$ & $-0.03(P=0.84)$ & $0.07(P=0.63$ & $0.08(P=0.60)$ & $0.06(P=0.68)$ \\
\hline Alx@75 & $-0.37(\mathrm{P}<0.00 \mathrm{I})$ & $-0.34(P<0.001)$ & $-0.31(P=0.02)$ & $-0.20(P=0.14)$ & $-0.38(P<0.01)$ & $-0.38(P<0.01)$ \\
\hline
\end{tabular}

Note: $\mathrm{P}<0.05$.

Abbreviations: Alx@75 beats $\mathrm{min}^{-1}$, augmentation index at a heart rate of 75 beats per minute; CSBP, central systolic blood pressure; CDBP, central diastolic blood pressure; $H R R_{1}$, heart rate recovery at the first minute of recovery; $H R R_{2}$, heart rate recovery at the second minute of recovery.

\section{Discussion}

The main findings of this study were that $\mathrm{HRR}_{1}$ and $\mathrm{HRR}_{2}$ were not associated with CSBP or CDBP in a combined group of men and women or in individual men and women groups. Additionally, we found that most measures of HRR were associated with AIx@75.

The finding of no association between $\mathrm{HRR}_{1}$ and CSBP suggests that as per $\mathrm{HRR}_{1}$, PNA was not associated with CSBP in this cohort of young participants. However, since slower HRR has been reported in older individuals who have higher blood pressure and arterial stiffness, ${ }^{4}$ if older participants were included in this study, then the result of this association could have been different. Here, age and health status would be important determinants of the association between $\mathrm{HRR}_{1}$ and CSBP. Previous works have demonstrated an association between HRR and AS, ${ }^{4,36}$ and AS has been found to be associated with central blood pressure. Since we measured AIx@75, in an effort to gain further insight into the lack of association between HRR and CSBP, we considered examining the association between AIx@75 and HRR. In this model, the augmentation of the forward pressure wave in the latter part of systole would only occur in the presence of AS and high pulse wave velocity. Here, the relative late systolic augmentation would be an indicator of increased pulse wave velocity and AS. However, such an examination might not be helpful in determining the association between HRR and AS. The lack of usefulness in using the association between HRR and AIx in this instance would indicate an understanding that certain misconceptions formed the basis for using AIx as an indicator of AS. One such misconception is regarding the backward pressure wave. Here, more current and detailed investigation $(n=13,770)$ indicates that the backward pressure wave peak is always found in late systole. ${ }^{37}$ This indication opposes the concept of the role the backward pressure wave plays in the determination of AS, as proposed by the previous model, and questions the validity 


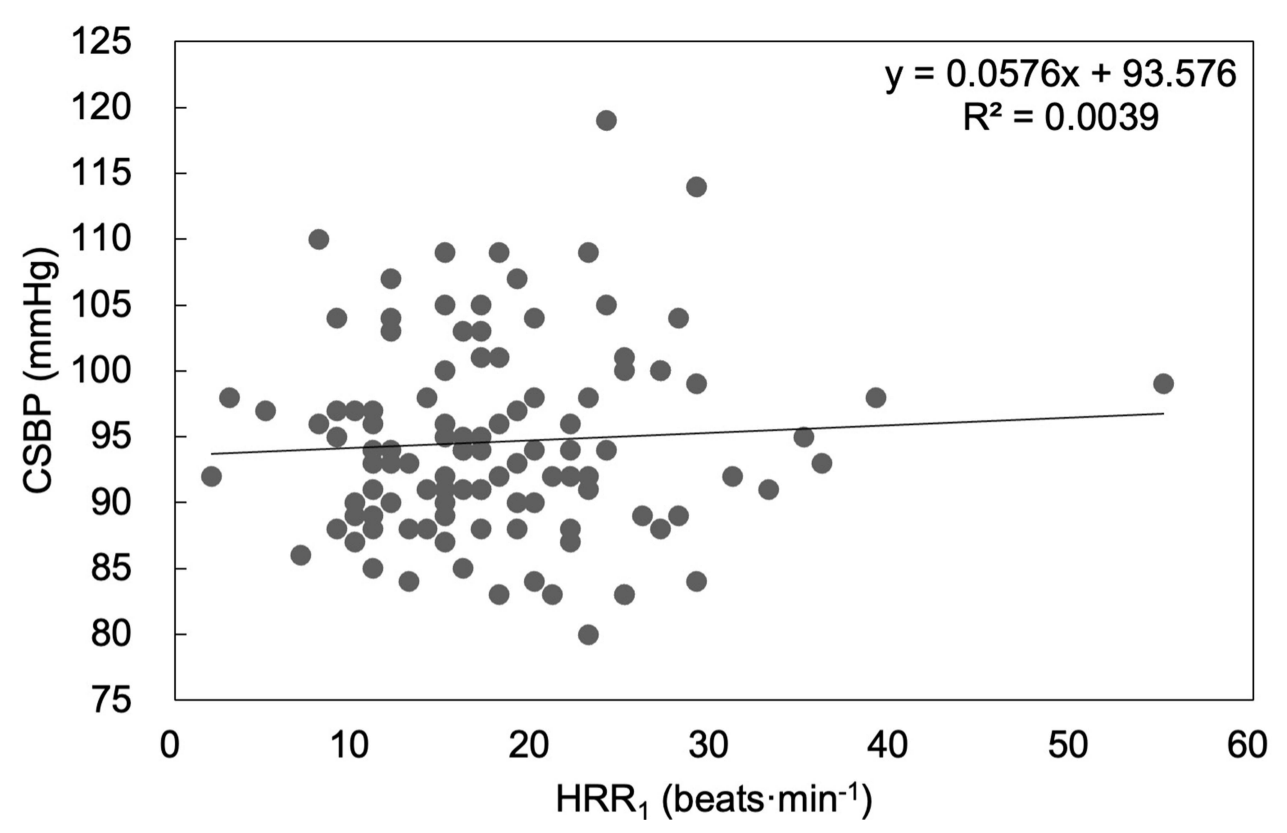

Figure I Correlation between $\mathrm{HRR}_{\mathrm{I}}$ and $\mathrm{CSBP}$ in a combined men and women group.

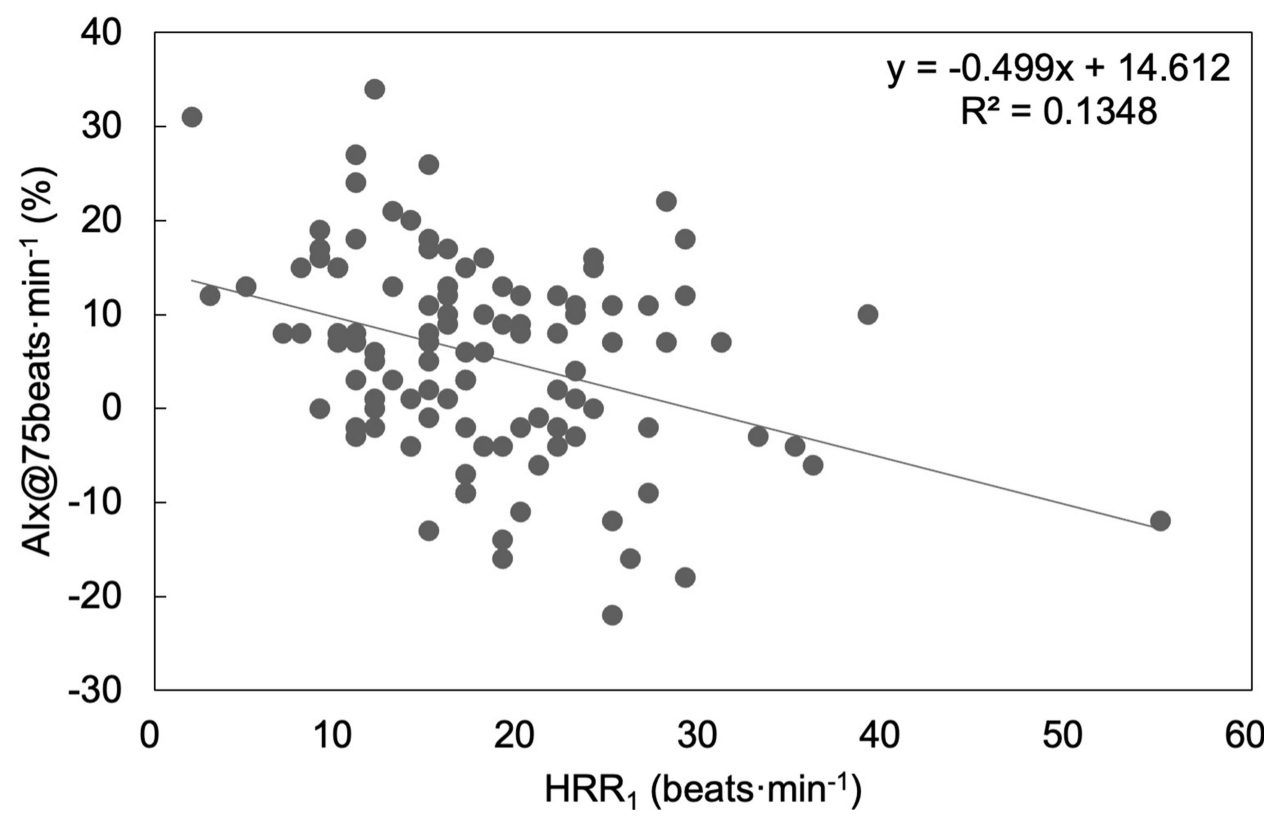

Figure 2 Correlation between HRR and Alx@75 in a combined men and women group.

of using AIx as a surrogate indicator of AS. This concept is supported by pharmacologic works, which indicate that AIx values changed immediately and dramatically after the infusion of vasoactive agents, ${ }^{38}$ especially nitric oxide-based agents. ${ }^{38,39}$ Here, AIx is considered to be more associated with systemic vascular resistance. Additionally, it has been proposed that AIx was inversely associated with AS. ${ }^{40}$ Therefore, we could not use AIx as an indicator of AS.

This study was designed to examine the association between HRR and CSBP in a cohort of young participants, and we found no association in this group of participants. Factors such as age and health status could have contributed to this finding. Unfortunately, due to the homogeneity of the participants, we were limited in examining further possibilities related to our finding. 


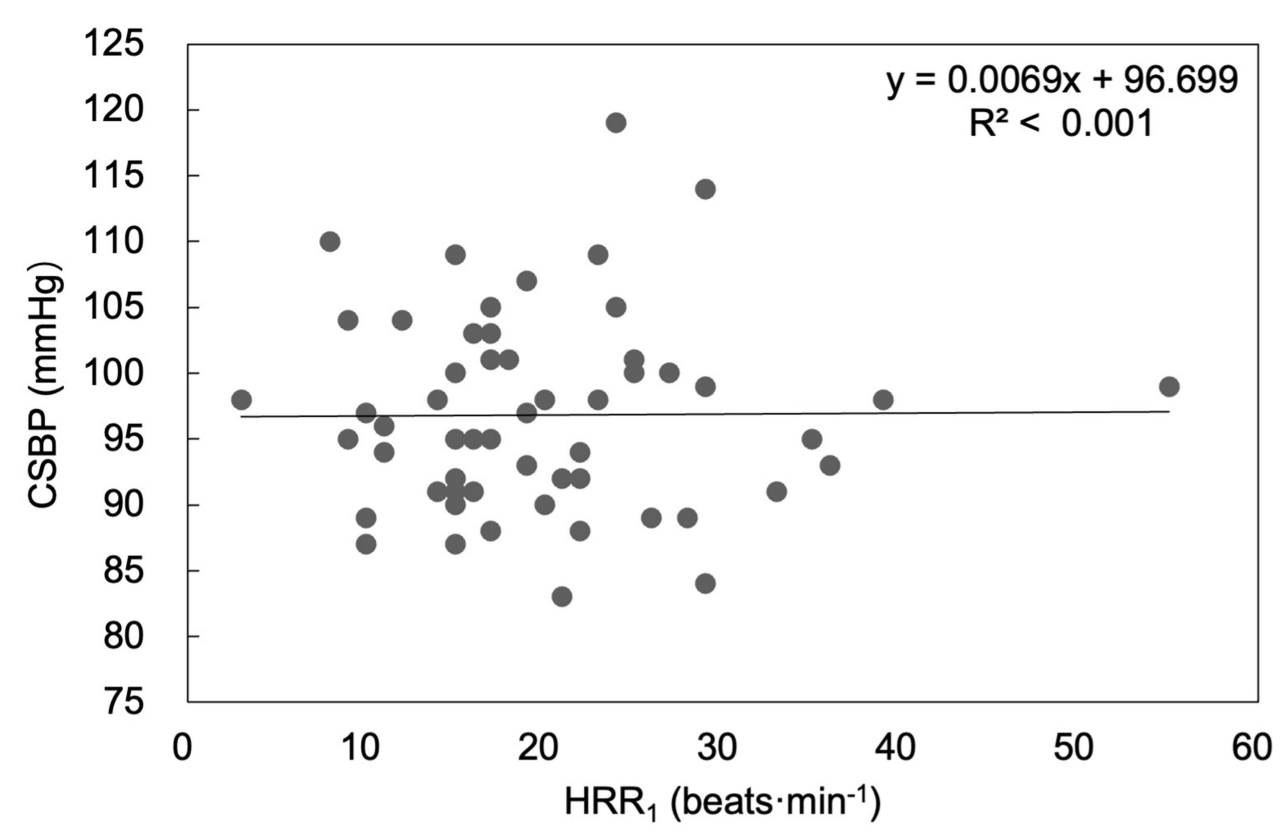

Figure 3 Correlation between $\mathrm{HRR}_{\mathrm{I}}$ and CSBP in men.

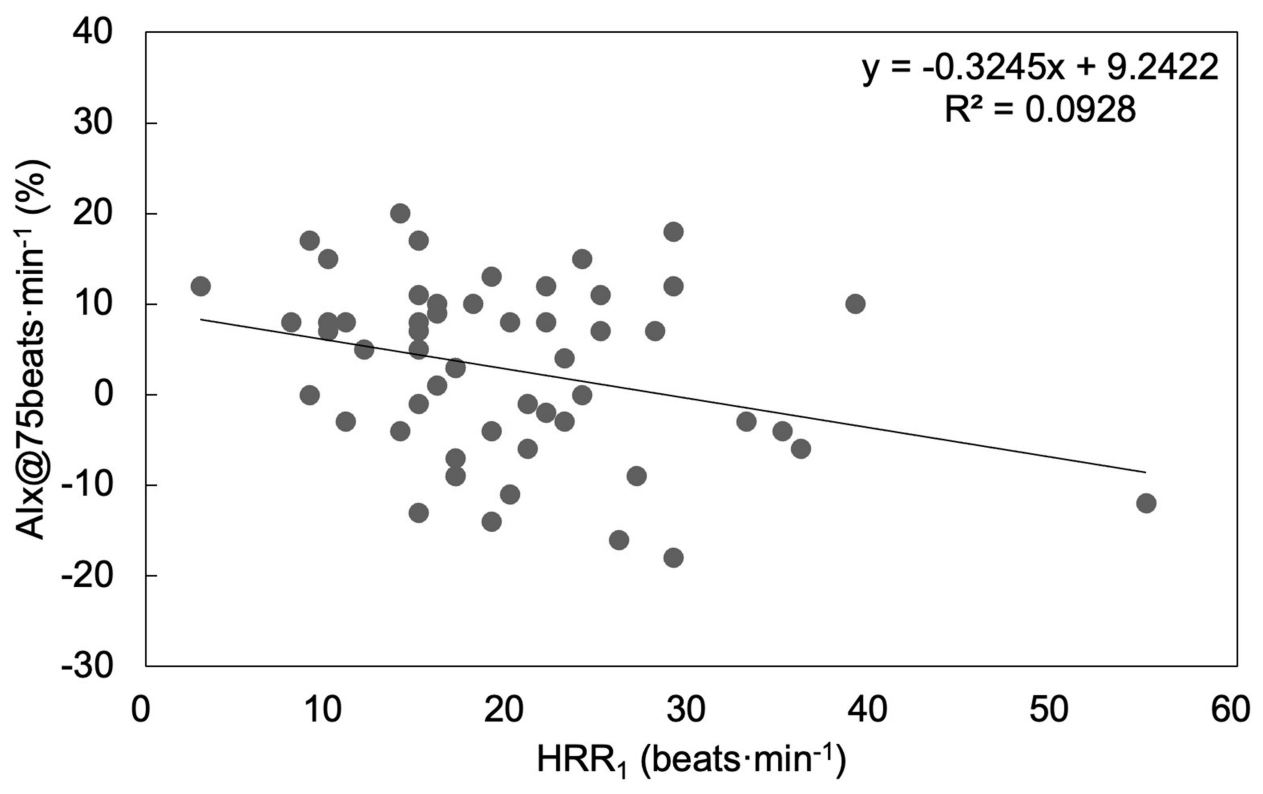

Figure 4 Correlation between HRR I and Alx@75 in men.

Much attention is now being given to including sex as a biological variable when developing study designs. ${ }^{41}$ This attention is particularly needed in cardiovascular research, since sex differences have been observed in autonomic function $^{42}$ and in elements of neurovascular control. ${ }^{43,44}$ Given these sex differences in cardiovascular parameters, we examined the association between measures of HRR, CSBP, and CDBP in men and women. Our findings indicated no associations between measures of HRR, CSBP, and CDBP in the individual men and women groups. This finding suggests that sex did not affect the association between measures of HRR, CSBP, and CDBP in young men and women under the age of 25 .

While the primary focus of this study was not to examine the association between HRR and AIx, we found that, except for the lack of association between $\mathrm{HRR}_{2}$ and AIx@75 in men, AIx@75 was negatively associated with all other 


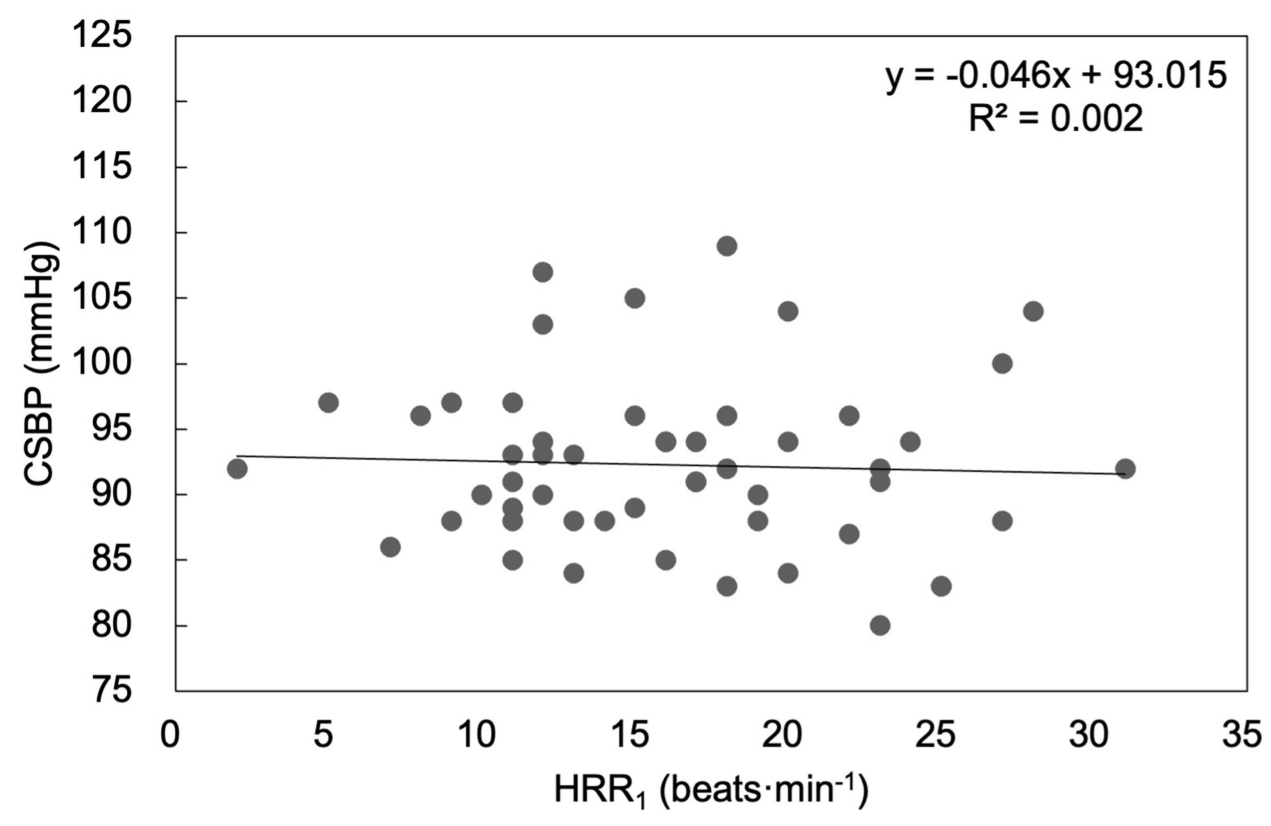

Figure 5 Correlation between $\mathrm{HRR}_{1}$ and CSBP in women.

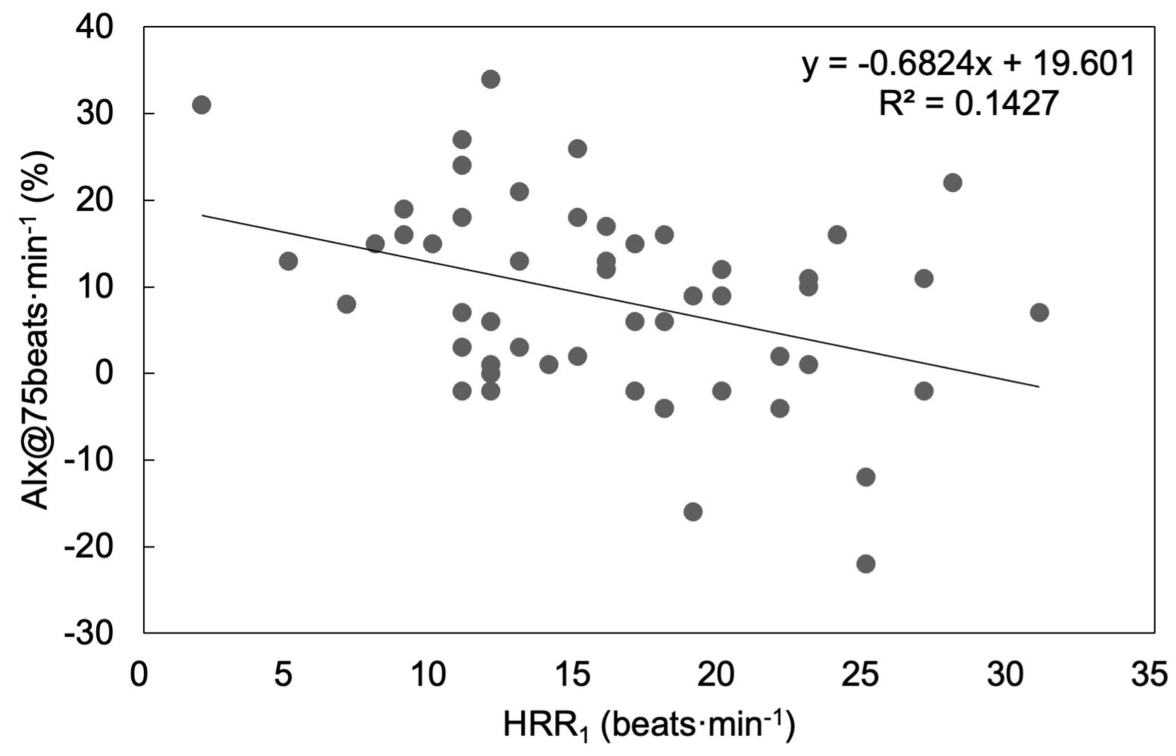

Figure 6 Correlation between $\mathrm{HRR}_{\mathrm{I}}$ and $\mathrm{Alx} @ 75$ in women.

Note: $P<0.05$

Abbreviations: Alx@75 beats min $^{-1}$, augmentation index at a heart rate of 75 beats per minute; CSBP, central systolic blood pressure; HRR , heart rate recovery at the first minute of recovery.

measures of HRR in both men and women. As mentioned earlier, there is a robust association between AIx and systemic vascular resistance, ${ }^{25}$ with vasoactive drugs, ${ }^{38}$ and the inhibition of basal nitric oxide synthase found to be associated with AIx. ${ }^{39}$ In the current study, most measures of HRR were found to be associated with AIx@75. Given the association between AIx and systemic vascular resistance, our observation seems to indicate that faster $\mathrm{HRR}_{1}$, which is more attributable to PNA versus SNA, is associated with reduced systemic vascular resistance in both men and women. Since $\mathrm{HRR}_{2}$ is more attributed to reduced SNA versus PNA, the finding of no association between $\mathrm{HRR}_{2}$ and AIx@75 in men 
suggests that sex could perhaps influence the association between measures of HRR and AIx when reduced SNA is the main contributing factor to HRR. While we are not certain of the clinical relevance of our finding, the observation of an association between HRR and AIx is particularly interesting since to the best of our knowledge such a finding has not been previously reported in young individuals.

The findings of no association between measures of HRR, CSBP, and CDBP in a combined group, and in men and women under 25 years of age, with sex not affecting that association, seem to suggest that though HRR can be a useful surrogate marker of cardiovascular health in certain populations, HHR might not be a helpful tool in extrapolating information regarding CSBP and CDBP in young individuals.

Based on findings in the current study, more work is needed to fully understand the association between measures of HRR and AIx and to determine the clinical relevance of this association. Such understandings could hold valuable information on using measures of HRR as a surrogate marker of cardiovascular function.

\section{Conclusion}

Measures of HRR were not associated with CSBP or CDBP in a combined group of healthy young men and women or based on sex. Most measures of HRR, especially the ones that PNA establishes, were associated with lower AIx. Though measures of HRR might be good indicators of cardiovascular disease, they might not be a good indicator of CSBP in young individuals. More work is needed then examining the association between HRR and AIx in young individuals.

\section{Disclosure}

The authors report no conflicts of interest related to this work.

\section{References}

1. Imai K, Sato H, Hori M, et al. Vagally mediated heart rate recovery after exercise is accelerated in athletes but blunted in patients with chronic heart failure. J Am Coll Cardiol. 1994;24(6):1529-1535. doi:10.1016/0735-1097(94)90150-3

2. Pierpont GL, Stolpman DR, Gornick CC. Heart rate recovery post-exercise as an index of parasympathetic activity. J Auton Nerv Syst. 2000;80 (3):169-174. doi:10.1016/S0165-1838(00)00090-4

3. Qiu S, Cai X, Sun Z, et al. Heart rate recovery and risk of cardiovascular events and all-cause mortality: a meta-analysis of prospective cohort studies. J Am Heart Assoc. 2017;6(5). doi:10.1161/JAHA.117.005505.

4. Yang IH, Hwang HJ, Jeon HK, et al. Slow heart rate recovery is associated with increased exercise-induced arterial stiffness in normotensive patients without overt atherosclerosis. J Cardiovasc Imaging. 2019;27(3):214-223. doi:10.4250/jcvi.2019.27.e27

5. Okutucu S, Karakulak UN, Aytemir K, Oto A. Heart rate recovery: a practical clinical indicator of abnormal cardiac autonomic function. Expert Rev Cardiovasc Ther. 2011;9(11):1417-1430. doi:10.1586/erc.11.149

6. Robinson BF, Epstein SE, Beiser GD, Braunwald E. Control of heart rate by the autonomic nervous system: studies in man on the interrelation between baroreceptor mechanisms and exercise. Circ Res. 1966;19(2):400-411. doi:10.1161/01.RES.19.2.400

7. Fagraeus L, Linnarsson D. Autonomic origin of heart rate fluctuations at the onset of muscular exercise. J Appl Physiol. 1976;40(5):679-682. doi:10.1152/jappl.1976.40.5.679

8. Bharadwaj M, Pope C, Davis M, Katz S, Cook C, Maxwell L. Subacute pyridostigmine exposure increases heart rate recovery and cardiac parasympathetic tone in rats. Clin Exp Pharmacol Physiol. 2017;44(8):872-879. doi:10.1111/1440-1681.12773

9. Sundaram S, Shoushtari C, Carnethon M, Kadish A, Goldberger J. Autonomic and nonautonomic determinants of heart rate recovery. Heart Rhythm. 2004;1(1):100-101.

10. Vivekananthan DP, Blackstone EH, Pothier CE, Lauer MS. Heart rate recovery after exercise is a predictor of mortality, independent of the angiographic severity of coronary disease. J Am Coll Cardiol. 2003;42(5):831-838. doi:10.1016/S0735-1097(03)00833-7

11. Lins TC, Valente LM, Sobral Filho DC, E Silva OB. Relation between heart rate recovery after exercise testing and body mass index. Rev Port Cardiol. 2015;34(1):27-33. doi:10.1016/j.repc.2014.07.006

12. Ho JS, Fitzgerald SJ, Barlow CE, et al. Risk of mortality increases with increasing number of abnormal non-ST parameters recorded during exercise testing. Eur J Cardiovasc Prev Rehabil. 2010;17(4):462-468. doi:10.1097/HJR.0b013e328336a10d

13. Park JI, Shin SY, Park SK, Barrett-Connor E. Usefulness of the integrated scoring model of treadmill tests to predict myocardial ischemia and silent myocardial ischemia in community-dwelling adults (from the Rancho Bernardo study). Am J Cardiol. 2015;115(8):1049-1055. doi:10.1016/j. amjcard.2015.01.536

14. Morita AA, Silva LKO, Bisca GW, et al. Heart rate recovery, physical activity level, and functional status in subjects with COPD. Respir Care. 2018;63(8):1002-1008. doi:10.4187/respcare.05918

15. Grassi G, Seravalle G, Mancia G. Sympathetic activation in cardiovascular disease: evidence, clinical impact and therapeutic implications. Eur $J$ Clin Invest. 2015;45(12):1367-1375. doi:10.1111/eci.12553

16. Florea VG, Cohn JN. The autonomic nervous system and heart failure. Circ Res. 2014;114(11):1815-1826. doi:10.1161/ CIRCRESAHA.114.302589

17. Barak OF, Klasnja A, Gacesa JP, Ovcin ZB, Grujic NG. Gender differences in parasympathetic reactivation during recovery from Wingate anaerobic test. Period Biol. 2014;116(1):53-58. 
18. Wang KL, Cheng HM, Chuang SY, et al. Central or peripheral systolic or pulse pressure: which best relates to target organs and future mortality? J Hypertens. 2009;27(3):461-467. doi:10.1097/HJH.0b013e3283220ea4

19. Roman MJ, Devereux RB, Kizer JR, et al. High Central pulse pressure is independently associated with adverse cardiovascular outcome. $J$ Am Coll Cardiol. 2009;54(18):1730-1734. doi:10.1016/j.jacc.2009.05.070

20. Lamarche F, Agharazii M, Madore F, Goupil R. Prediction of cardiovascular events by type I central systolic blood pressure. Hypertension. 2021;77 (2):319-327. doi:10.1161/HYPERTENSIONAHA.120.16163

21. Izzo JJL. Brachial vs. central systolic pressure and pulse wave transmission indicators: a critical analysis. Am J Hypertens. 2014;27(12):1433-1442. doi:10.1093/ajh/hpu135

22. Mitchell GF. Central pressure should not be used in clinical practice. Artery Res. 2015;9(C):8-13. doi:10.1016/j.artres.2014.11.002

23. Hayward CS, Kelly RP. Gender-related differences in the central arterial pressure waveform. J Am Coll Cardiol. 1997;30(7):1863-1871. doi:10.1016/S0735-1097(97)00378-1

24. Costa-Hong VA, Muela HCS, Macedo TA, Sales ARK, Bortolotto LA. Gender differences of aortic wave reflection and influence of menopause on central blood pressure in patients with arterial hypertension. BMC Cardiovasc Disord. 2018;18(1):123. doi:10.1186/s12872-018-0855-8

25. Wilenius M, Tikkakoski AJ, Tahvanainen AM, et al. Central wave reflection is associated with peripheral arterial resistance in addition to arterial stiffness in subjects without antihypertensive medication. BMC Cardiovasc Disord. 2016;16(1):1-11. doi:10.1186/s12872-016-0303-6

26. Chirinos JA, Kips JG, Jacobs JDR, et al. Arterial wave reflections and incident cardiovascular events and heart failure: MESA (Multiethnic Study of Atherosclerosis). J Am Coll Cardiol. 2012;60(21):2170-2177. doi:10.1016/j.jacc.2012.07.054

27. Latchman PL, Thiel R, Gates G, et al. Cardiovagal tone: a predictor of heart rate adjusted augmentation index in men but not in women. Open J Mol Integr Physiol. 2017;7(3):41-51. doi:10.4236/ojmip.2017.73004

28. Leicht AS, Hirning DA, Allen GD. Heart rate variability and endogenous sex hormones during the menstrual cycle in young women. Exp Physiol. 2003;88(3):441-446. doi:10.1113/eph8802535

29. Miyashita H. Clinical assessment of central blood pressure. Curr Hypertens Rev. 2012;8(2):80-90. doi:10.2174/157340212800840708

30. Nelson MR, Stepanek J, Cevette M, Covalciuc M, Hurst T, Tajik AJ. Noninvasive measurement of central vascular pressures with arterial tonometry: clinical revival of the pulse pressure waveform? Mayo Clin Proc. 2010;8(5):460-472. doi:10.4065/mcp.2009.0336

31. Wilkinson IB, MacCallum H, Flint L, Cockcroft JR, Newby DE, Webb DJ. The influence of heart rate on augmentation index and central arterial pressure in humans. $J$ Physiol. 2000;525(1):263-270. doi:10.1111/j.1469-7793.2000.t01-1-00263.x

32. O’Rourke MF, Pauca A, Jiang XJ. Pulse wave analysis. Br J Clin Pharmacol. 2001;51(6):507-522. doi:10.1046/j.0306-5251.2001.01400.x

33. Pauca AL, O'Rourke MF, Kon ND. Prospective evaluation of a method for estimating ascending aortic pressure from the radial artery pressure waveform. Hypertension. 2001;38(4):932-937. doi:10.1161/hy1001.096106

34. Chen $\mathrm{CH}$, Nevo E, Fetics B, et al. Estimation of central aortic pressure waveform by mathematical transformation of radial tonometry pressure. Circulation. 1997;95(7):1827-1836. doi:10.1161/01.CIR.95.7.1827

35. Bruce RA, Blackmon JR, Jones JW, Strait G. Exercising testing in adult normal subjects and cardiac patients. Pediatrics. 1963;32(4):742-756. doi:10.1542/peds.32.4.742

36. Fei DY, Arena R, Arrowood JA, Kraft KA. Relationship between arterial stiffness and heart rate recovery in apparently healthy adults. Vasc Health Risk Manag. 2005;1(1):85-89. doi:10.2147/vhrm.1.1.85.58938

37. Baksi AJ, Treibel TA, Davies JE, et al. A meta-analysis of the mechanism of blood pressure change with aging. J Am Coll Cardiol. 2009;54 (22):2087-2092. doi:10.1016/j.jacc.2009.06.049

38. Kelly RP, Millasseau SC, Ritter JM, Chowienczyk PJ. Vasoactive drugs influence aortic augmentation index independently of pulse-wave velocity in healthy men. Hypertension. 2001;37(6):1429-1433. doi:10.1161/01.HYP.37.6.1429

39. Wilkinson IB, MacCallum H, Cockcroft JR, Webb DJ. Inhibition of basal nitric oxide synthesis increases aortic augmentation index and pulse wave velocity in vivo. Br J Clin Pharmacol. 2002;53(2):189-192. doi:10.1046/j.1365-2125.2002.1528adoc.x

40. Vyas M, Izzo JL Jr, Lacourciere Y, et al. Augmentation index and central aortic stiffness in middle-aged to elderly individuals. Am J Hypertens. 2007;20(6):642-647. doi:10.1016/j.amjhyper.2007.01.008

41. National Institutes of Health. NIH policy on sex as a biological variable. Available from: https://orwh.od.nih.gov/sex-gender/nih-policy-sexbiological-variable. Accessed September 2, 2020.

42. Farrell MC, Giza RJ, Shibao CA. Race and sex differences in cardiovascular autonomic regulation. Clin Auton Res. 2020;30(5):371-379. doi:10.1007/s10286-020-00723-z

43. Hissen SL, Taylor CE. Sex differences in vascular transduction of sympathetic nerve activity. Clin Auton Res. 2020;30(5):381-392. doi:10.1007 s10286-020-00722-0

44. Taylor CE, Arnold AC, Fu Q, Shibao CA. Sex differences in cardiovascular autonomic control: introduction to the special issue. Clin Auton Res. 2020;30(5):365-367. doi:10.1007/s10286-020-00732-y

Vascular Health and Risk Management

Dovepress

\section{Publish your work in this journal}

Vascular Health and Risk Management is an international, peer-reviewed journal of therapeutics and risk management, focusing on concise rapid reporting of clinical studies on the processes involved in the maintenance of vascular health; the monitoring, prevention and treatment of vascular disease and its sequelae; and the involvement of metabolic disorders, particularly diabetes. This journal is indexed on PubMed Central and MedLine. The manuscript management system is completely online and includes a very quick and fair peer-review system, which is all easy to use. Visit http://www.dovepress.com/testimonials.php to read real quotes from published authors.

Submit your manuscript here: https://www.dovepress.com/vascular-health-and-risk-management-journal 